
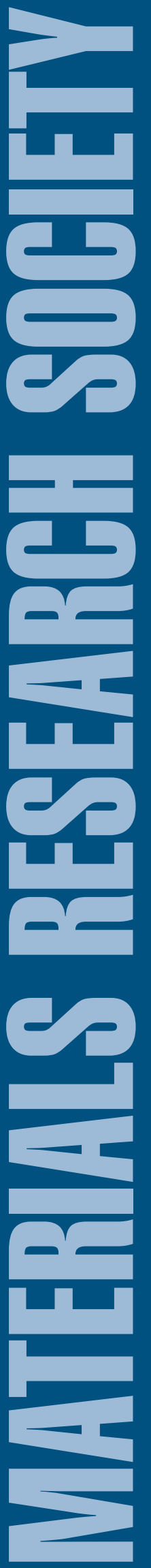

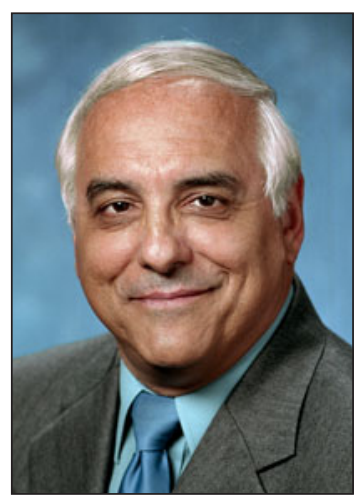

The Materials Research Society recognizes that diversity drives innovation, excellence, and new discoveries.

\section{Diversity drives innovation, excellence, and new discoveries}

\section{www.mrs.org/diversity}

Orlando Auciello

2013 MRS President

Research shows that diverse working groups are more productive, creative, and innovative, and engage at a higher level of critical analysis, than homogeneous groups.* Diversity is critical to innovation and the advancement of science and technology and their impact on global economic leadership.

The scientific and engineering communities must strive to become more inclusive, engaging all geographic and demographic groups in advancing science and technology. The Materials Research Society recognizes that diversity drives innovation, excellence, and new discoveries. Although progress has been made, segments of our worldwide scientific community still remain a largely untapped resource in research and innovation.

For these reasons, the MRS Board of Directors developed and approved a Diversity Statement a few years ago. The complete Diversity Statement can be found on the MRS website, but I would like to share an excerpt with you:

"The Materials Research Society therefore charges our membership and our leaders to continually engage the science and engineering enterprise, promoting greater participation from all demographic groups, proactively addressing barriers, and fostering greater diversity wherever scientists and engineers are educated and employed."

We are not where we want to be yet, but with the help of the MRS Diversity Subcommittee and the MRS Women in Science and Engineering Subcommittee, we have made progress. Some recent and planned activities include:

- the launch of a graduate student mentoring program, which provides opportunities for under-represented minorities and others to be mentored by senior scientists;

- Materials Research Society Foundation support for the Workshop on Ethnic Diversity in Materials Science and Engineering (December 2012);

- Women in Materials Science and Engineering Breakfast Panel at the 2013 MRS Spring Meeting - "Diversity in STEM: climbing the corporate ladder in academia, government, and private industry"; 
- planned events for under-represented minority students in the US National Science Foundation's Partnership for Research and Engineering in Materials (PREM) Program at the 2013 MRS Fall Meeting and through two-way live streaming; and

- planned expansion of the mentoring program to undergraduate students from minority-serving institutions.

During the 2013 MRS Spring Meeting, MRS volunteer leaders convened to review the current state of geographic and demographic diversity within MRS and to explore a path to improvement. One area of focus will be increasing diversity in award nominations. In reviewing the data, Fellows and other MRS award nominees are predominantly male and from the United States of America (USA). Additionally, Graduate Student Award winners have primarily been from institutions in the USA. Short-term actions designed to expand diversity in award nominations and applications will be implemented over the coming months, and a longer term plan is under development.

We still have work to do. The MRS Board of Directors and the MRS Member Engagement Committee are committed to improving geographic and demographic diversity within MRS and its committees. But we need your help!

I challenge each of you to set aside five minutes today to decide what action you, personally, can take to foster diversity within MRS and within your own organization. When you think about nominating a colleague for an MRS award, including MRS Fellow, think broadly and globally. Volunteer to become an MRS mentor. Encourage graduate students from outside the USA to apply for a Graduate Student Award. Support the PREM events at the 2013 MRS Fall Meeting. Reach out to colleagues and students who are part of underrepresented groups and encourage them to become engaged in MRS. Join the MRS Diversity Subcommittee. There are many options and many opportunities for you to contribute.

"No one can do everything, but everyone can do something. "’ I have witnessed great accomplishments when MRS members unite; and if we all work together, I am confident that we can create an environment where researchers from all backgrounds can thrive and strengthen the worldwide materials community!

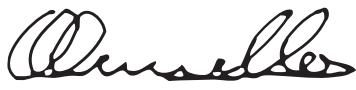

Orlando Auciello

2013 MRS President

${ }^{\star}$ S. Kerby, C. Burns, The Top 10 Economic Facts of Diversity in the Workplace (Center for American Progress, July 12, 2012)

†M. Lucado, Outlive Your Life: You Were Made to Make a Difference (Thomas Nelson, Inc., 2010). 